\title{
Family Presence in Long-Term Care During the COVID-19 Pandemic: Call to Action for Policy, Practice, and Research
}

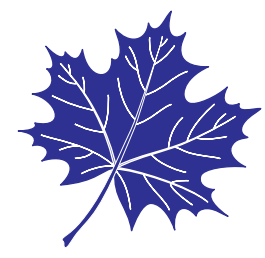

Susan M. Tupper, PT, $\mathrm{PhD}^{1}$, Heather Ward, MD, MSc, FRCPC ${ }^{2}$, Jasneet Parmar, MBBS, MCFP(COE), MSC ${ }^{3}$

${ }^{I}$ Quality, Safety \& Strategy, Saskatchewan Health Authority, Royal University Hospital, Saskatoon, SK;

${ }^{2}$ Department of Medicine, University of Saskatchewan, Saskatoon, SK; ${ }^{3}$ Department of Family Medicine,

University of Alberta, Edmonton, $A B$

https://doi.org/10.5770/cgj.23.476

Key words: long-term care; pandemics; caregivers; policy; public health

\section{INTRODUCTION}

On March 11, 2020 the World Health Organization recognized coronavirus disease 2019 (COVID-19) as a global pandemic.

(1) By March 27, 2020 public health states of emergency had been declared in all of Canada's provinces and territories as a means of containing the rapid and exponential spread of COVID-19. This gave governments the authority to close schools, restrict business operations, and limit the size of public gatherings. Visitation restrictions in health-care settings were enacted, with all non-essential visitors prohibited from entering facilities. Congregate living residential homes for older adults, such as long-term care (LTC) and personal care homes, were included in these restrictions in order to reduce potential for risk of transmission between residents, staff, and visitors. Initially, visitation policies were highly restrictive, classifying spouses/partners and adult children of residents in the same category as entertainers, except for "compassionate care" reasons that were poorly defined and inconsistently applied. Over the ensuing months, policies became more flexible and allowed case-by-case assessment of visits deemed essential. Provincial policies continue to differ and lack detail regarding who would be responsible to classify a visitor as essential and what criteria would be used to make these judgments. ${ }^{(2)}$

Ideological perspectives, informed by available evidence, influence the writing, interpretation, and enactment of policies. (3) Restricting family presence in LTC may lead to confinement syndrome, moral distress, complicated grief associated with bereavement, and poorer resident health outcomes, ${ }^{(4-7)}$ yet this approach was rigorously enacted for the first three months of the pandemic. Even after public health regulations began to allow limited visits, some homes continued to restrict access, claiming prevention of harm as the motivation. ${ }^{(8)}$ The longer restrictions are kept in place, the more likely residents and families will either suffer in quality of life, or die without being able to spend their final weeks or months with loved ones. ${ }^{(9)}$

Family caregivers (FCGs) provide $70-90 \%$ of the care for Canadians living with complex conditions, frailty, and impairments. ${ }^{(10)}$ Within LTC, FCGs account for up to $30 \%$ of care including feeding, washing, toileting, social, emotional and memory support, and mobilization. ${ }^{(11)}$ They are often unseen as they are not the "patient" in a system predicated on the needs of the care recipient, yet they are key partners in LTC, relied upon to provide care, but inconsistently included as part of the circle of care and care planning. The initial Public Health Agency of Canada guidance for infection prevention and control of COVID-19 in LTC homes recommended, "Restricting visitors and volunteers to only those essential for basic personal, medical or compassionate resident care."(12) Lack of resident and family involvement in co-designing policy and shared decision-making in health systems resulted in more restrictive approaches to interpretation of this recommendation, and subsequent policy development and organizational implementation. ${ }^{(13)}$

The matter is clearly not simple, with implications for harm both with restrictive and flexible policies. More flexible policies are expected to support maintenance of family units and resident physical and psychosocial well-being; however, an incremental increase of individuals entering the facility may present a risk of spreading or contracting infection. With high rates of asymptomatic and mild symptom presentations with COVID-19, the degree of risk is difficult to ascertain on symptom screening alone. ${ }^{(14)}$ Research to inform policies on family presence during the pandemic, as well as a nuanced and compassionate approach to writing and enacting policies, is required which acknowledges these complexities. The purpose of this commentary is to review the impact of restriction of family presence on residents, families, and LTC staff, and provide a resident/family-oriented perspective on 
policy, practice, and research implications to challenge the outdated notion of "one-size-fits-all" visitation restrictions during a pandemic.

\section{Impact of Restriction of Family Presence}

Long-term care (LTC) homes are a high-risk setting for infection spread and poor outcomes from COVID-19.(7) Given LTC accounts for over $80 \%$ of Canadian COVID-19 fatalities, attention to effective infection control measures is essential. ${ }^{(15)}$ However, infection spread is not the only concern for LTC homes during this time. ${ }^{(16)}$ Media reports of dire conditions in homes in two provinces that required military intervention highlight the need for increased scrutiny of LTC models of care, funding, and oversight. ${ }^{(17-18)}$ Although visitation restrictions are common during infectious outbreaks, COVID-19 presents a unique situation in both the duration of the restrictions and the application of restrictions, even when homes are not experiencing an outbreak and rates of community transmission are low. A balance needs to be maintained between attending to patients' physical and psychological needs and adhering to infection control guidelines, while offering psychological support to family members. ${ }^{(19)}$

Family presence improves quality of life and reduces resident mortality. ${ }^{(20)}$ Inconsistencies in both care and health-care errors are more likely to occur when families are not able to be present to alert staff to potential problems or to assist with unique care needs. ${ }^{(21)}$ Common physical and cognitive impacts for long-term care residents from restriction of family presence include deterioration of nutritional and hydration status, weight loss, depressed mood, increased responsive behaviours, worsened signs and symptoms of dementia, and reduced mo-

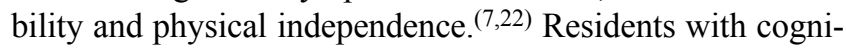
tive, memory, or communication impairments or those whose primary language is not spoken by staff are more vulnerable to negative impacts as they may have less capacity to understand the situation or use alternate approaches to physical visits such as social media, telephone or video conferencing. ${ }^{(23)}$

Families restricted from providing care grieve over the loss of companionship and the care-giving role. ${ }^{(9)}$ Prolonged separation may also affect the ability of residents with dementia to recognize family members, which could further compound the sense of grief and loss for families. Long-term impacts of complicated grief have been reported by family members of patients and residents who die during periods of visitation restriction. ${ }^{(5)}$ Staff members also report increased workload, stress, sadness, and vicarious trauma from bearing witness to patient/resident loneliness and distress from isolation, having to take on additional "familial" roles, or navigating angry responses from patients and family members who deem the restrictions unjust. ${ }^{(6)}$

\section{Policy Implications}

Infection control policies for LTC homes will be dissimilar to other health-care settings due to differences in populations, built environments, staff mobility, funding, and access to resources. Likewise, family presence policies must also reflect these differences, as well as models of care offered that are inclusive of emotional and social needs. As a primary place of residence, maintenance of family units in LTC must be prioritized with acknowledgement that the word 'visitation' does not adequately describe the presence of some family members. ${ }^{(9)}$ Policies must protect the rights of residents and families to be equal partners making decisions about who may enter their residence, rather than simply being informed or consulted. When case-by-case decision-making is required to determine who is granted access during pandemic restrictions, organizational policies need to clearly outline the process or rubric by which these decisions are made and who is involved. Guidelines for a rapid appeal and response process must be established and publicly displayed for families who may feel that a decision to restrict is not justified. Furthermore, homes must be held accountable by provincial funders to respect the decisions made by the appeals committee. Family presence cannot be restricted to a poorly defined "end-of-life" circumstance, as was seen in the early restrictions of COVID-19.(24) Residents of LTC are in their final months and years of life, with length of stay decreasing with transition to age-in-place programs. Provision of end-of-life care in LTC should also guide decisions on family presence. ${ }^{(25)}$

Enhanced communication is essential in order to mitigate the negative impacts of visitation restrictions. ${ }^{(9)}$ Family presence policies must mandate a communication strategy for LTC homes, defining the need to maintain contact between residents and families, and between key family representatives and knowledgeable care staff. Such a strategy should include proactive contacting of family representatives to identify preferred frequency and modes of visits or communication with staff who can report on residents' status.

\section{Practice Implications}

Provincial funding organizations may need to proactively increase staff levels or repurpose staff, such as social workers and recreational therapists, to support communication, psychosocial, education, and infection control needs of residents and families during a pandemic. ${ }^{(26,27)}$ Education and reminders must be provided for families who enter LTC homes on self-monitoring a wide range of possible illness presentations, physical distancing, isolation before, between and after visits, and infection control practices such as hand hygiene, respiratory etiquette, and PPE donning and doffing. Consideration should be given to allow designated family members to co-habit on site for patients/residents who are most vulnerable to negative physical and psychosocial outcomes from visitation restrictions, such as those with higher physical and psychosocial support needs and those who cannot use alternate forms of communication. Particular attention to palliative care and dying is needed to ensure that no one dies alone, and that the dying experience is humane and does not contribute to long-term negative grief experiences for families. ${ }^{(5)}$ Policies must ensure that advanced care plans that engage FCGs in care planning are in place for each resident and accessible to staff. ${ }^{(28)}$ 
Informal support networks or virtual town halls for information sharing and support give families the opportunity to learn from, and be supported by, peers. ${ }^{(29)}$ Family members require information on potential mental health impacts of visitation restrictions and contact information for available services. Frequently updated detailed information on pandemic plans and infection control activities must be communicated by organizations (i.e., facilities or government organizations responsible for pandemic plans) in order to counteract potentially misleading or fear-invoking information in the media and on social media. ${ }^{(30)}$

Residents and families must be recognized members of the care team, as opposed to persons "entrusted" to the care of a facility and "visitors". A position statement from the Regional Geriatric Programs of Ontario and the Canadian Geriatric Society describes FCGs and the provision of essential care. ${ }^{(19)}$ FCGs also need information, training, care, and support to support caregiver-centred care provision. ${ }^{(31)}$ Caregiver-centred care is a collaborative working relationship between families and health and community care professionals, with professionals supporting FCGs in their caregiving role. This approach respects and meaningfully involves the residents' FCGs in the planning and delivery of supportive services, recognizing caregivers needs and preferences, and integrating FCGs as partners in care. ${ }^{(32)}$ Health-care provider training may also be needed to support care approaches that recognize families alongside health-care professionals as team members, with the skills to support residents and families especially during times of distress. Figure 1 provides a multilevel interdisciplinary stakeholder co-designed definition of competency domains for caregiver-centred care. ${ }^{(10)}$

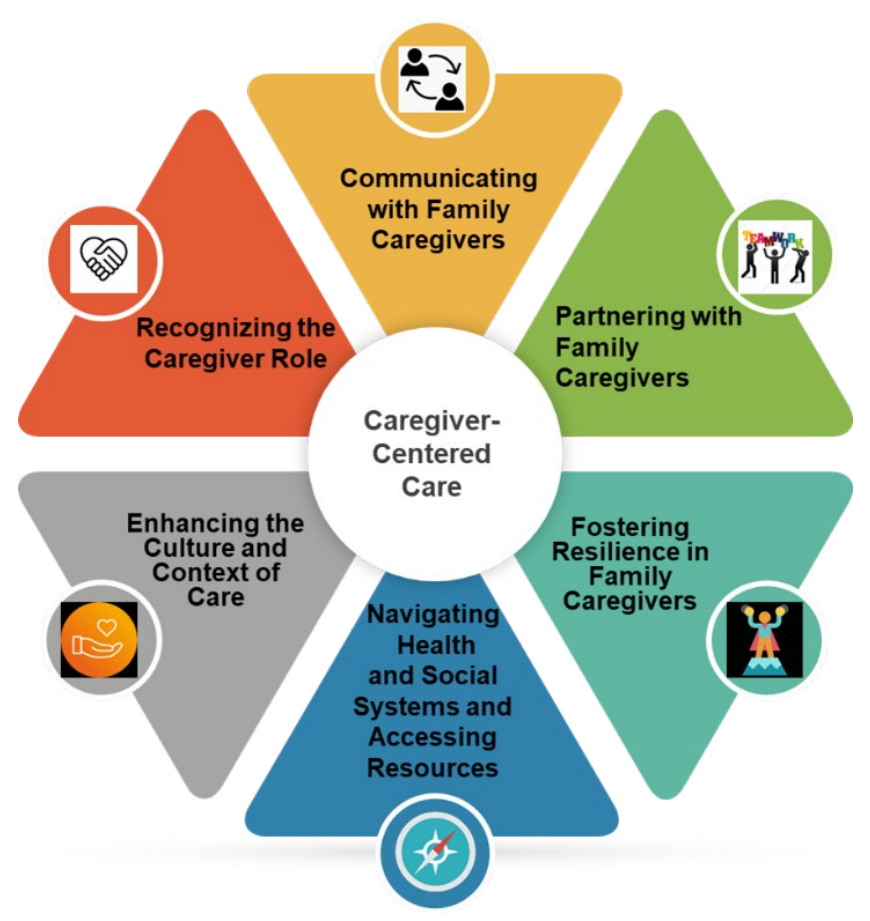

FIGURE 1. Caregiver-centred competency domains ${ }^{(10)}$

\section{Research Implications}

To better inform future pandemic policies, modelling studies are needed to examine the impact of human resource, built environment, and staff, resident, and family mobility and infection control practices that minimize infection spread and maximize family presence. For example, does family presence in fact reduce infection spread and improve resident outcomes by reducing wandering of residents with dementia between rooms? What are the implications of social isolation on resident and FCG health and well-being? Outcome data collection on LTC resident outcomes, such as the Resident Assessment Instrument (RAI), is paramount to identify impacts of social isolation.

Very little guidance has been provided in the literature on innovative approaches to engage FCGs during a pandemic. The literature mainly focuses on supporting alternate forms of communication such as telephone calls, or technologyassisted communication through social media, video/voice calls, or virtual reality (VR). ${ }^{(33)}$ Further research is needed on the impact of technology-assisted communication and physical distancing visits on psychosocial outcomes. Prerecorded VR videos that allow the viewer to virtually 'leave' the hospital or LTC home have been used in palliative care and with residents with moderate and advanced dementia. $(34,35)$ Live-stream VR that can be used to connect residents with friends and families through a virtual space may be a way to make connections during outbreak restrictions, as well for as families separated by geographic distance. ${ }^{(36)}$ Prior to the pandemic, recognition of FCGs as partners in clinical decision-making focused on communication and dialogue as a standard approach to care. ${ }^{(37)}$ Evidence-informed policy to support communication strategies and resources designed to include FCGs in care conferences and shared decision-making need to be developed and evaluated, with family experience and satisfaction as key measures of effectiveness.

\section{CONCLUSIONS}

Prioritization of infection control measures without ensuring that psychosocial needs are protected and family engagement is supported is a short-sighted approach that, over time, will lead to resident, family, and LTC staff harm. Maintaining a balance between infection control practices and family engagement through an open family presence policy requires ongoing discussion that draws from available literature and clinician and family experiences. Policies must reflect that residents and families are viewed as partners on the care team, rather than passive recipients of care. This distinction, along with the engagement of families in residents' lives, is particularly important during stressful times of a pandemic.

\section{ACKNOWLEDGEMENTS}

The authors acknowledge members of the Saskatchewan Long-term Care Network. Their expertise and experiences in LTC, before and during the pandemic, informed the content 
and messages of this commentary. Thank you to Kirstie Gibson for assistance with manuscript preparation, and the Saskatchewan Health Authority and University of Saskatchewan librarians for detailed searches of published and grey literature of this rapidly evolving subject material.

\section{CONFLICT OF INTEREST DISCLOSURES}

The authors declare that no conflicts of interest exist.

\section{REFERENCES}

1. World Health Organization. WHO Director-General's opening remarks at the media briefing on COVID-19-11 March 2020. Geneva, Switzerland: The World Health Organization; 2020. Available from: https:/www.who.int/dg/speeches/detail/whodirector-general-s-opening-remarks-at-the-media-briefing-oncovid-19---11-march-2020

2. Public Health Physicians of Canada. Snapshot of long-term care facility visitation policies across Canadian province and territories. Ottawa, ON: Public Health Physicians of Canada; 2020. Available from: http://www.phpc-mspc.ca/resources/Documents/ Respository/PHPC_Scan_LTC\%20policies_22Jun2020.pdf

3. Rosella LC, Wilson K, Crowcroft NS, et al. Pandemic H1N1 in Canada and the use of evidence in developing public health policies: a policy analysis. Soc Sci Med. 2013;83:1-9.

4. Purssell E, Gould D, Chudleigh J. Impact of isolation on hospitalised patients who are infectious: systematic review with meta-analysis. BMJ Open. 2020;10(2):e030371.

5. Wallace CL, Wladkowski SP, Gibson A, et al. Grief during the COVID-19 pandemic: considerations for palliative care providers. J Pain Symptom Manage. 2020;60(1):e70-e76.

6. Yardley S, Rolph M. Death and dying during the pandemic [editorial]. BMJ. 2020;369:m1472.

7. Diamantis S, Noel C, Tarteret P, et al. Severe acute respiratory syndrome coronavirus 2 (SARS-CoV-2)-related deaths in French long-term care facilities: the "confinement disease" is probably more deleterious than the coronavirus disease-2019 (COVID-19) itself [letter to the editor]. JAMDA. 2020;21(7):989-90.

8. Vescera Z. Husband of dementia patient frustrated by longterm care visit restrictions. Saskatoon Star Phoenix [Internet]. 2020 June 12 [cited June 29]; Local News:[about 4 screens]. Available from: https://thestarphoenix.com/news/local-news/ six-feet-apart-doesnt-cut-it-for-husband-of-dementia-patient

9. Hart JL, Turnbull AE, Oppenheim IM, et al. Family-centered care during the COVID-19 era. J Pain Symptom Manage. 2020; 60(2):393-397.

10. Parmar J, Brémault-Phillips S, Duggleby W, et al. Caregivercentered care competency framework: education for health providers to support family caregivers. Edmonton, AB: Alberta Covenant Health Network of Excellence in Senior's Health; 2019. Available from: https://seniorsnetworkcovenant.ca/wpcontent/uploads/2020-06-02-Competency-Framework.pdf

11. Ansah JP, Koh V, Qureshi MA, et al. Modeling to inform longterm care policy and planning for an aging society. IN: Abarbanel HDI, Braha D, Erdi P, et al., editors. Understanding Complex Systems. Berlin: Springer; 2017. Chapter 7, p. 183-224.

12. Public Health Agency of Canada. Public Health Agency of Canada releases interim guidance for infection prevention and control of COVID-19 for long-term care homes [News Release, April 13, 2020]. Ottawa, ON: Public Health Agency of Canada; 2020. Available from: https://www.canada.ca/en/public-health/ news/2020/04/public-health-agency-of-canada-releases-interimguidance-for-infection-prevention-and-control-of-covid-19-forlong-term-care-homes.html

13. Richards T, Scowcroft H. Patient and public involvement in covid-19 policy making [editorial]. BMJ. 2020;370:m2575.

14. Arons MM, Hatfield KM, Reddy SC, et al. Presymptomatic SARS-CoV-2 infections and transmission in a skilled nursing facility. N Engl J Med. 2020;382(22):2081-90.

15. Canadian Institute for Health Information. Pandemic experience in the long-term care sector: how does Canada compare with other countries [CIHI snapshot June 2020]. Ottawa, ON: Canadian Institute for Health Information; 2020. Available from: https://www.cihi.ca/sites/default/files/document/covid19-rapid-response-long-term-care-snapshot-en.pdf?emktg lang $=$ en\&emktg_order $=1$

16. Ellis $P$. The benefits and drawbacks of open and restricted visiting hours. Nursing Times [Internet]. 2018 Nov 12 [cited 2020 July 4];114:12,18-20. Available from: https://www.nursingtimes.net/clinical-archive/patient-experience/the-benefits-anddrawbacks-of-open-and-restricted-visiting-hours-12-11-2018/

17. Boisvert N. Ontario long-term care homes in scathing report could face charges, says Ford. CBC News [Internet]. 2020 May 26 [cited June 29]; Toronto:[about 7 screens]. Available from: https://www.cbc.ca/news/canada/toronto/ontario-military-ltcreport-1.5585131

18. Holroyd-Leduc JM, Laupacis A. Continuing care and COVID-19: a Canadian tragedy that must not be allowed to happen again [editorial]. CMAJ. 2020;192(23):e632-e633.

19. Regional Geriatric Programs of Ontario. Family presence in older adult care: a statement regarding family caregivers and the provision of essential care. Toronto, ON: Regional Geriatric Programs of Ontario; 2020. Available from: https://rgps.on.ca/ resources/family-presence-in-older-adult-care-a-statementregarding-family-caregivers-and-the-provision-of-essential-care/

20. Gardner W, States D, Bagley N. The coronavirus and the risks to the elderly in long-term care. J Aging Soc Policy. 2020;32(4-5): $310-15$.

21. Institute for Patient and Family Centred Care. Changing hospital "visiting" policies and practices: supporting family presence and participation. Bethesda, MD: Institute for Patient and Family Centred Care; 2010. Available from: https://www.ipfcc.org/ resources/visiting.pdf

22. Welsh M. The brutal blow that pandemic isolation has dealt residents of long-term care residences. Toronto Star [Internet]. 2020 June 28 [cited July 4]; Canada:[about 9 screens]. Available at: https://www.thestar.com/news/canada/2020/06/28/ what-pandemic-isolation-has-done-to-ltc-residents.html

23. Noone C, McSharry J, Smalle M, et al. Video calls for reducing social isolation and loneliness in older people: a rapid review. Published 2020 May 22. Cochrane Database Syst Rev. 2020;5:1-42.

24. Planetree. Person-centered guidelines for preserving family presence in challenging times - May 28, 2020. Derby, CT: Planetree; 2020. Available from: https://www.planetree.org/ hubfs/Downloads/Guidelines\%20on \%20Preserving\%20Family $\% 20$ Presence $\% 20$ During\%20Challenging\%20Times $\% 205$. 28.20.pdf

25. Hoben M, Chamberlain SA, Gruneir A, et al. Nursing home length of stay in 3 Canadian health regions: temporal trends, 


\section{TUPPER: FAMILY PRESENCE IN LTC DURING COVID}

jurisdictional differences, and associated factors. $\mathrm{J} \mathrm{Am} \mathrm{Med} \mathrm{Dir}$ Assoc. 2019;20(9):1121-28.

26. Trabucchi M, De Leo D. Nursing homes or besieged castles: COVID-19 in Northern Italy. Lancet Psychiartry. 2020;7(5): 387-88.

27. McCleary L, Munro M, Jackson L, et al. Impact of SARS visiting restrictions on relatives of long-term care residents. $J$ Soc Work Long Term Care. 2005;3(3/4):3-20.

28. Gordon A, Burns E, Vardy E, et al. COVID-19: Managing the COVID-19 pandemic in care home for older people. London, UK: British Geriatrics Society; 2020. Available from: https:// www.bgs.org.uk/resources/covid-19-managing-the-covid19-pandemic-in-care-homes

29. Family Councils Ontario. Updates: Virtual family forums [Internet]. Toronto, ON: Family Councils Ontario; 2020 [cited 2020 June 4]. Available from: https://www.fco.ngo/updatesand-events/updates/virtual-family-forums

30. The World Health Organization. Mental health and psychosocial considerations during the COVID-19 outbreak. Published 2020 March 18. Geneva, Switzerland: The World Health Organization; 2020. Available at: https://www.who.int/docs/ default-source/coronaviruse/mental-health-considerations. pdf?sfvrsn=6d3578af_2

31. Schulz R, Beach SR, Friedman EM, et al. Changing structures and processes to support family caregivers of seriously ill patients. J Palliat Med. 2018;21(S2):S36-S42.

32. Wolff JL, Feder J, Schulz R. Supporting family caregivers of older Americans. New Engl J Med. 2016;375(26):2513-35.

33. Volling C, Popalyar A, Defalco K, et al. Infection prevention and control for COVID-19: interim guidance for long term care homes. Ottawa, ON: National Advisory Committee on Infection Prevention and Control; 2020. Available from: https:// www.canada.ca/en/public-health/services/diseases/2019-novelcoronavirus-infection/prevent-control-covid-19-long-termcare-homes.html

34. Niki K, Okamoto Y, Maeda I, et al. A novel palliative care approach using virtual reality for improving various symptoms of terminal cancer patients: a preliminary prospective, multicenter study. J Palliat Med. 2019;22(6):702-07.

35. Hayhurst J. How augmented reality and virtual reality is being used to support people living with dementia - design challenges and future directions. IN: Jung T, Claudia tom Dieck M, editors. Augmented Reality and Virtual Reality. Berlin: Springer; 2017. Chapter 20, p. 295-305.

36. Zhang J, Wang H, Dong L. Family member visits to critically ill patients during COVID-19: a new pathway [letter to the editor]. Telemed J E Health. 2020;26(7):853. [Online ahead of print]

37. Parmar J, Torti J, Brémault-Phillips S, et al. Supporting family caregivers of seniors within acute and continuing care systems. Can Geriatr J. 2018;21(4):292-96.

Correspondence to: Susan M Tupper, PT, PhD, Quality, Safety \& Strategy, Saskatchewan Health Authority, Ellis Hall Room 435, Royal University Hospital, 103 Hospital Dr., Saskatoon, SK, Canada, S7N 0W8

E-mail: susan.tupper@usask.ca 